\title{
Characterizing Offenses of Junior High School Students in a University from 2015 to 2018
}

\author{
Belinda V. Deeney \\ Staff, Prefect of Discipline
}

\section{Mauro Allan P. Amparado \\ Director, Community Awareness, Relations \& Extension Services \\ mapamparado@gmail.com}

\section{University of Cebu Lapu-Lapu and Mandaue Mandaue City, Cebu, Philippines}

Keywords: Discipline; Light offenses; Serious offenses; Junior High School; Mandaue City, Cebu, Philippines

\section{Abstract}

This study ascertained the light and serious offenses incurred by Junior High School Students from SY 2015-2016 to SY 2017-2018. The findings served as basis for recommendations.

This study is a descriptive quantitative study which utilized secondary data from the Office of the Prefect of Discipline in University of Cebu Lapu-Lapu and Mandaue, Mandaue City, Cebu, Philippines. Data was retrieved from June 2015 to May 2018. The offenses were categorized as light and serious offenses. Simple percentage was used to analyze the data.

Findings revealed that majority of the Junior High School students who committed light and serious offenses were male and from Grade 9. 
For SY 2015-2016, data shows that offenses were highest for the months of September 2015, December 2015 and January 2016. A total of 15 light offenses and 63 serious offenses were incurred during this school year. For SY 20162017, offenses were highest for the months of August 2016, October 2016 and February 2017. A total of 233 light offenses and 195 serious offenses were incurred during this school year. For SY 2017-2018, offenses were highest for the months of July 2017, August 2017, and September 2017. A total of 233 light offenses and 195 serious offenses were incurred during this school year.

It was noted that there was an increase in the number of offenses from SY 2015-2016 to SY 2016-2017. Moreover, there was a decline of incurred offenses from SY 2016-2017 to SY 2017-2018.

Based on the findings of the study, the number of offenses has decreased. However, with the numbers seen on a yearly basis, the Office of the Prefect of Discipline may strengthen their periodical campaign to improve compliance of students to school policies and departmental guidelines.

Keywords: Junior High School; Light Offenses; Serious Offenses; Mandaue City, Cebu, Philippines

Recommended citation: Deeney, B. V. \& Amparado, M. A. P. (2020). Characterizing Offenses of Junior High School Students in a University from 2015 to 2018. Cebu Journal of Teacher Education, 1(2), 78-90. 


\section{Introduction}

"No discipline seems pleasant at the time, but painful. Later on, however, it produces a harvest of righteousness and peace for those who have been trained by it." - Hebrews 12:11

Transition in behavior from elementary to junior high school is difficult for student as well as their mentors and other school authority. Particularly, in imposing discipline among the young is quite a tedious and challenging task for discipline implementers. Not only it is critical as to the issue on abuse but might be a violation against certain laws and a clear disparity on the child protection law implemented by the Department of Education which aims to protect children from all forms of physical or mental violence, injury and abuse, neglect or negligent treatment, maltreatment and exploitation, including sexual abuse (DepEd Order No.40, s.2012).

The implementation of policy on discipline might be construed as a form of abuse and implementers may be held liable for it. That, in the academic institution adopt strategies to impose self-discipline through proper observance of school rules and regulations with a thorough process to uphold students' rights to due process.

In UCLM, there is an increasing number of students' misbehaviour ranging from light offenses like unprescribed haircut, non-wearing of uniform, habitual tardiness, truancy and the serious offenses like bullying, fist fighting, unethical use of social media and disrespect to school personnel. Thus, the need to conduct or explore the causes in order to establish strategies to effectively curtail and modify the students' behaviour to mold them to become self-disciplined and a 
highly competitive and productive individual as they venture towards achieving better academic mileage.

These further motivate the researcher to continue exploring the behaviors of students in order to have a better understanding of the millennials behavioural manifestation and to be able to enhance the strategies adopted to improve implementation to effectively modify students' behaviour. 


\section{Theoretical Background}

This study is anchored on Sutherland's Differential Association Theory, which is expressed as a series of nine fundamental principles: (1) criminal behavior is learned, which means that criminal before is not inherited, as such, also, the person who is not already trained in crime does not invent criminal behavior, just as a person does not make mechanical inventions unless he or she has had training in mechanics; (2) criminal behavior is learned in interaction with other persons in a process of communication- this communication is verbal in many respects but also includes the communication of gestures; (3) the principal part of the learning of criminal behavior occurs within intimate personal groups, negatively this means that the impersonal agencies of communication, such as movies and newspapers, play a relatively unimportant part in the genesis of criminal behavior; (4) learning criminal behavior includes learning the techniques of committing crime, which are sometimes very complicated, and learning the specific direction of motives, drives, rationalization and attitudes; (5) the specific direction of motives and drives is learned from definitions of the legal codes as favorable or unfavorable. In some societies, an individual is surrounded by persons who invariably define the legal codes as rules to be observed, while in others he or she is surrounded by persons whose definitions are favorable to the violation of the legal codes as favorable or unfavorable; and (6) a person becomes delinquent because of an excess of definitions favorable to violations of law over definitions favorable of the law. It refers to both criminal and anti-criminal associations and has to do with counteracting forces. When persons become criminals, they do so because of contacts with criminal patterns and also because of isolation from anti criminal patterns (Holmes, Maahs \& Vito, 2006). 
The Theory of Planned Behavior by Ajzen is based on the assumption that human being usually behave in a sensible manner; that they take account of available information and implicitly or explicitly consider the implications of their actions. The theory further postulates that a person's intention to perform (or not to perform) a behavior is the most important immediate determinant of that action. Intentions and behavior are a function of three basic determinants, one personal in nature, one reflecting social influence, and a third dealing with issues of control (Ajzen, 2005).

Student misbehaviors such as disruptive talking, chronic avoidance of work, clowning, interfering with teaching activities, harassing classmates, verbal insults, rudeness to teacher, defiance, and hostility, ranging from infrequent to frequent, mild to severe, is a thorny issue in everyday classroom. Teachers usually reported that these disturbing behaviors in the classroom are intolerable and stressprovoking, and they had to spend a great deal of time and energy to manage the classroom. Obviously, student misbehaviors retard the smoothness and effectiveness of teaching and also impede the learning of the student and his/her classmates. Moreover, research findings have shown that school misbehavior not only escalated with time but also lowered academic achievement and increased delinquent behavior. To lessen these immediate and gradual adverse effects of student misbehaviors, it is of primary importance to identify what exactly are these behaviors inside classroom (Sun \& Sheck, 2012).

Another important aspect which necessitates the proper handling of student misconduct refers to the safety of fellow learners and school staff. It is important that teachers respond immediately to minor incidents of misconduct before they can 
escalate into more serious difficulties that can pose a threat to the safety of school communities.

In many schools worldwide, there appears to be a need for additional, legally sound methods to deal with student misconduct more effectively. Traditional methods applicable to typical student misconduct such as detention, the setting of school and classroom rules, demerit points, and corporal punishment are effectively applied in some situations but in others they prove to be less effective. Many educational practitioners claim that the majority of these traditional methods are less effective while others argue that the application of corporal punishment proves to be one of the most effective methods in dealing with learner misconduct. Yet, in many countries corporal punishment in schools is regarded as unconstitutional or deemed to be inhuman and degrading (Russo et.al., 2014).

\section{Related Studies}

Various studies have been conducted on discipline and offenses. In the study of Yahaya (2009) findings showed that the causes of truant are at the medium level and types of truant are at the low level. Activities done during truant such as helping the family, joining the negative groups, crime are at the low level and working part-time together with loafing are at the medium level.

In another study, African Americans are overrepresented in school suspensions, yet little is known about the underlying contributing dynamics. Study 1 reviewed a high school's annual discipline data and 442 students referred for defiance. African Americans were over-represented in referrals for defiance and most students received referrals from one or several teachers. This suggests that defiance 
referrals are specific to the classroom situation. Examining the situational specificity of referrals, Study 2 used repeated measures and multilevel modelling with a sub-sample of 30 African American students. Attendance, grades, and teacher reports showed that students behaved more defiantly and less cooperatively with teachers perceived as having untrustworthy authority. Predictors of African American student trust in teacher authority included teacher caring and high expectations, offering implications for lowering the discipline gap (Gregory \& Weinstein, 2008).

Serrano and Amparado analyzed the disciplinary process at the College of Nursing, University of Cebu Banilad, Cebu City, Cebu, Philippines. The study revealed that nursing students who committed misdemeanors perceived that administrators, teachers, and disciplinary committee members have less support in the disciplinary process (2015).

\section{Objectives}

This study ascertained the light and serious offenses incurred by Junior High School Students from SY 2015-2016 to SY 2017-2018. The findings served as basis for recommendations.

\section{Methods}

This study is a descriptive quantitative study which utilized secondary data from the Office of the Prefect of Discipline in University of Cebu Lapu-Lapu and Mandaue, Mandaue City, Cebu, Philippines. Data was retrieved from June 2015 to May 2018. The offenses were categorized as light and serious offenses. Simple percentage was used to analyze the data. 
Table 1 presents the profile of the Junior High School students who committed light and serious offenses. The table shows that there were more male than female offenders within the last three years (976 offenders). In terms of grade level, there were more offenders coming from Grade 9 (369 offenders).

Table 1. Profile of the subjects

\begin{tabular}{|l|c|c|c|c|}
\hline Profile & $\begin{array}{c}\text { SY 2015- } \\
\mathbf{2 0 1 6}\end{array}$ & $\begin{array}{c}\text { SY 2016- } \\
\mathbf{2 0 1 7}\end{array}$ & $\begin{array}{c}\text { SY 2017- } \\
\mathbf{2 0 1 8}\end{array}$ & Total \\
\hline Gender & & & & \\
\hline Male & 69 & 520 & 387 & 976 \\
\hline Female & 9 & 90 & 41 & 140 \\
\hline Total & 78 & 610 & 428 & 1,116 \\
\hline $\begin{array}{l}\text { Grade } \\
\text { Level }\end{array}$ & & & & \\
\hline 7 & 10 & 84 & 73 & 167 \\
\hline 8 & 18 & 131 & 104 & 253 \\
\hline 9 & 32 & 191 & 144 & 367 \\
\hline 10 & 18 & 204 & 107 & 329 \\
\hline Total & 78 & 610 & 428 & 1,116 \\
\hline
\end{tabular}




\section{Results and Discussion}

This section presents the light and serious offenses incurred by students from 2015 to 2018. Table 1 shows the summary of offenses for SY 2015-2016. Data shows that offenses were highest for the months of September 2015, December 2015 and January 2016. A total of 15 light offenses and 63 serious offenses were incurred during this school year.

\section{Table 1. Summary of Offenses SY 2015-2016}

\begin{tabular}{|l|c|c|c|}
\hline \multicolumn{1}{|c|}{ Month } & $\begin{array}{c}\text { Light } \\
\text { Offenses }\end{array}$ & $\begin{array}{c}\text { Serious } \\
\text { Offenses }\end{array}$ & Total \\
\hline June & 0 & 3 & 3 \\
\hline July & 1 & 4 & 5 \\
\hline August & 7 & 2 & 9 \\
\hline September & 0 & 15 & 15 \\
\hline October & 0 & 0 & 0 \\
\hline November & 0 & 6 & 6 \\
\hline December & 7 & 11 & 18 \\
\hline January & 0 & 11 & 11 \\
\hline February & 0 & 5 & 5 \\
\hline March & 0 & 6 & 6 \\
\hline Total & 15 & 63 & 78 \\
\hline
\end{tabular}


Table 2 shows the summary of offenses for SY 20162017. Data shows that offenses were highest for the months of August 2016, October 2016 and February 2017. A total of 233 light offenses and 195 serious offenses were incurred during this school year.

It was noted that there was an increase in the number of offenses from SY 2015-2016 to SY 2016-2017.

\section{Table 2. Summary of Offenses SY 2016-2017}

\begin{tabular}{|l|c|c|c|}
\hline \multicolumn{1}{|c|}{ Month } & $\begin{array}{c}\text { Light } \\
\text { Offenses }\end{array}$ & $\begin{array}{c}\text { Serious } \\
\text { Offenses }\end{array}$ & Total \\
\hline June & 4 & 12 & 16 \\
\hline July & 19 & 19 & 38 \\
\hline August & 56 & 53 & 109 \\
\hline September & 32 & 18 & 50 \\
\hline October & 59 & 33 & 92 \\
\hline November & 10 & 4 & 14 \\
\hline December & 13 & 6 & 19 \\
\hline January & 16 & 7 & 23 \\
\hline February & 189 & 18 & 207 \\
\hline March & 18 & 24 & 42 \\
\hline Total & 416 & 194 & 610 \\
\hline
\end{tabular}

Table 3 presents the summary of offenses for SY 20172018. Data shows that offenses were highest for the months of July 2017, August 2017, and September 2017. A total of 233 light offenses and 195 serious offenses were incurred during this school year.

It was noted by the researchers that there was a decline of incurred offenses from SY 2016-2017 to SY 2017-2018. 
Table 3. Summary of Offenses SY 2017-2018

\begin{tabular}{|l|c|c|c|}
\hline \multicolumn{1}{|c|}{ Month } & $\begin{array}{c}\text { Light } \\
\text { Offenses }\end{array}$ & $\begin{array}{c}\text { Serious } \\
\text { Offenses }\end{array}$ & Total \\
\hline June & 22 & 14 & 36 \\
\hline July & 36 & 21 & 57 \\
\hline August & 41 & 24 & 65 \\
\hline September & 41 & 27 & 68 \\
\hline October & 14 & 23 & 37 \\
\hline November & 24 & 8 & 32 \\
\hline December & 8 & 7 & 15 \\
\hline January & 19 & 19 & 38 \\
\hline February & 9 & 33 & 42 \\
\hline March & 19 & 19 & 38 \\
\hline Total & 233 & 195 & 428 \\
\hline
\end{tabular}

\section{Conclusion}

Based on the findings of the study, the number of offenses has decreased. However, with the numbers seen on a yearly basis, the Office of the Prefect of Discipline may strengthen their periodical campaign to improve compliance of students to school policies and departmental guidelines.

\section{Literature Cited}

Ajzen, I. (2005). Attitudes, personality, and behavior. McGraw-Hill Education (UK).

DepEd Order No. 40 Series of 2012. DepEd Child Protection Policy.

Gregory, A., \& Weinstein, R. S. (2008). The discipline gap and 
African Americans: Defiance or cooperation in the high school classroom. Journal of School Psychology, 46(4), 455-475.

Holmes, R. M., Maahs, J. R., \& Vito, G. F. (2006). Criminology: Theory, Research, and Policy.

Russo, C. J., Oosthuizen, I., \& Wolhuter, C. C.

(2014). International Perspectives on Student Behavior: What We Can Learn (Vol. 2). Rowman \& Littlefield.

Serrano, S. M. P. \& Amparado, M. A. P. (2015). Analysis of the Disciplinary Program: Misdemeanors, Support and Challenges. Journal of Research in Nursing, 1(1), 80-89.

Sun, R. C., \& Shek, D. T. (2012). Student classroom misbehavior: an exploratory study based on teachers' perceptions. The Scientific World Journal, 2012.

Yahaya, A., Ramli, J., Hashim, S., Ibrahim, M. A.,

Rahman, R. R., \& Yahaya, N. (2009). Discipline problems among secondary school students in Johor Bahru, Malaysia. European Journal of Social Sciences, 11(4), 659-675. 